\title{
Development of a high throughput yeast-based screening assay for human carbonic anhydrase isozyme II inhibitors
}

\author{
Anyaporn Sangkaew ${ }^{1}$, Jerapan Krungkrai $^{2}$ and Chulee Yompakdee ${ }^{1^{*}}$ (1)
}

\begin{abstract}
Carbonic anhydrase (CA; EC 4.2.1.1) catalyzes the reversible hydration of carbon dioxide $\left(\mathrm{CO}_{2}\right)$ to bicarbonate and proton. There are 16 known isozymes of a-CA in humans, which differ widely in their kinetics, subcellular localization and tissue-specific distribution. Several disorders are associated with abnormal levels of CA, and so the inhibition of CA has pharmacological application in the treatment of many diseases. Currently, searching for novel CA inhibitors (CAl) has been performed using in vitro methods, and so their toxicity remains unknown at the time of screening. To obtain potentially safer CAls, a screening procedure using an in vivo assay seems to have more advantages. Here, we developed a yeast-based in vivo assay for the detection of inhibitors of the human CA isozyme II (hCAll). The yeast Saccharomyces cerevisiae mutant deprived of its own CA ( $\triangle$ nce 103 strain) can grow under a high $\mathrm{CO}_{2}$ condition (5\% $(\mathrm{v} / \mathrm{v}) \mathrm{CO}_{2}$ ) but not at an ambient level. We constructed $\triangle n c e 103$ strains expressing various levels of hCAll from a plasmid harboring the hCAll gene arranged under the control of variously modified GAL1 promoter and relying on the expression of hCAll for growth under low $\mathrm{CO}_{2}$ condition. Using a multidrug-sensitive derivative of the $\triangle n c e 103$ strain expressing a low level of hCAll, we finally established a high throughput in vivo assay for hCAll inhibitors under a low $\mathrm{CO}_{2}$ condition. Cytotoxicity of the candidates obtained could be simultaneously determined under a high $\mathrm{CO}_{2}$ condition. However, their inhibitory activities against other CA isozymes remains to be established by further investigation.
\end{abstract}

Keywords: Human carbonic anhydrase isozyme II, Saccharomyces cerevisiae, Yeast-based assay, Resazurin, NCE103, Carbonic anhydrase inhibitor

\section{Introduction}

Carbonic anhydrases (CAs, EC 4.2.1.1) belong to the metalloenzymes family of proteins. They are a class of enzymes catalyzing the simple but physiologically essential process of carbon dioxide $\left(\mathrm{CO}_{2}\right)$ hydration to bicarbonate and proton $\left(\mathrm{CO}_{2}+\mathrm{H}_{2} \mathrm{O} \leftrightarrow \mathrm{HCO}_{3}{ }^{-}+\mathrm{H}^{+}\right)$. Overall, CAs play important roles in $\mathrm{pH}$ regulation, fluid balance, carboxylation reactions, calcification, bone resorption, tumorigenicity and in other pathological and physiological processes, such as gluconeogenesis, ureagenesis and lipogenesis (Supuran and Scozzafava 2000). Six different genetically distinct CA families have been described

\footnotetext{
${ }^{*}$ Correspondence: chulee.y@chula.ac.th

${ }^{1}$ Department of Microbiology, Faculty of Science, Chulalongkorn

University, Bangkok, Thailand

Full list of author information is available at the end of the article
}

to date; namely the $\alpha$ - (present in vertebrates, bacteria, algae and cytoplasm of green plants), $\beta$ - (predominantly in bacteria and algae), $\gamma$ - (mainly in archaea and some bacteria), $\delta$ - and $\zeta$ - (present in marine diatoms) and $\eta$-CA (present in parasite) (Del Prete et al. 2014; Lindskog 1997; Supuran 2008). Sixteen $\alpha$-CA isozymes have been found in humans, which differ widely in their kinetics, subcellular localization, tissue-specific distribution and susceptibility to different inhibitors. However, they all play important physiological roles, as briefly outlined above (Supuran and Scozzafava 2000). Many human $\mathrm{CA}$ isozymes are established therapeutic targets for the treatment of a wide range of disorders (Sly and Hu 1995; Supuran 2008; Supuran and Scozzafava 2000). Indeed, antiobesity, antiepilectic, anticancer and antiglaucoma drugs based on CA inhibitors (CAIs) are presently used, 
and they target various human CA isoforms (Carta and Supuran 2013; Masini et al. 2013; Monti et al. 2013; Scozzafava et al. 2013; Supuran 2008).

Sulfonamide compounds, which are classical CAI, have been used as commercial drugs for the treatment of glaucoma, epilepsy, edema and altitude sickness (Supuran 2008). However, they can inhibit all CA isoforms nonspecifically, diluting the drug effectiveness and causing undesired side effects from the off-target inhibition. Furthermore, a small but significant percentage of patients cannot be treated with sulfonamide-based compounds owing to their sulfa allergy (Lomelino et al. 2016). Thus, safer CAIs are required. In previous studies, CAIs were screened for by in vitro methods using a biochemical strategy, but this approach has several disadvantages. For example, it provides no information about drug uptake into cells, drug stability and, in particular, the cytotoxicity of the compounds (Bilsland et al. 2013). Such disadvantages could be improved by using an in vivo assay.

The yeast Saccharomyces cerevisiae has emerged in the last few decades as a powerful organism for the study of many human enzymes. The deep genetic information available on this organism has allowed it to become an increasingly popular model for pharmacological and/or drug discovery studies (Daniel et al. 2005). The $\Delta$ nce103 null mutation leads to the loss of endogenous CA activity and inhibits the growth of the yeast cells under an ambient $\mathrm{CO}_{2}$ concentration (Clark et al. 2004) due to the low level of available bicarbonate ions in the absence of $\mathrm{CA}$ activity.

Human carbonic anhydrase isozyme II (hCAII) is the most efficient isozyme in $\mathrm{CO}_{2}$ hydration and is a highly abundant CA isozyme in cells (Supuran and Scozzafava 2000). Furthermore, hCAII is the only isozyme so far reported in which its overexpression can complement the growth defect of the yeast $\Delta n c e 103$ null mutant strain (Clark et al. 2004). Thus, in this study, we aimed to develop a novel yeast-based assay in a 96-well format for the high throughput screening of CAIs against hCAII.

Here, a highly sensitive $\Delta$ nce 103 null yeast strain expressing hCAII was constructed and used for screens in a resazurin microtiter plate assay (REMA). The developed yeast-based assay enables high-throughput, livecell, target-based screening to identify compounds that could inhibit hCAII activity. Hence, it could be a potential tool for accelerating the discovery of non-sulfonamide-based CAIs to be used for the treatment CArelated diseases, such as glaucoma.

\section{Materials and methods} Microbial strains and cultivation media Escherichia coli DH5 $\alpha$ [F-endA1 hsdR17 ( $\mathrm{r}-\mathrm{K} / \mathrm{m}-\mathrm{K})$ supE44 thi-1 $\lambda$-recA1 gyrA96 $\Delta$ lacU169 ( $\$ 80$ lacZ $\Delta$ M15)]
Table 1 Yeast strains used in this study

\begin{tabular}{|c|c|c|}
\hline Yeast strain & Genotype & Reference \\
\hline W303-1A & $\begin{array}{l}\text { MATa ade2-1 his3-11 leu2-3,112 } \\
\text { trp1-1 ura3-1 can1-100 }\end{array}$ & $\begin{array}{l}\text { Yeast Genetic } \\
\text { Resources Center, } \\
\text { Japan }\end{array}$ \\
\hline ASO1 & $\begin{array}{l}\text { MATa ade2-1 his3-11 leu2- } \\
\text { 3,112 trp1-1 ura3-1 can1-100 } \\
\text { nce103::IoxP }\end{array}$ & This study \\
\hline ASO2 & $\begin{array}{l}\text { MATa ade2-1 his3-11 leu2- } \\
\text { 3,112 trp1-1 ura3-1 can 1-100 } \\
\text { nce103::IoxP erg3::IoxP }\end{array}$ & This study \\
\hline BY25929 & $\begin{array}{l}\text { MATa ade2-1 his3-11 leu2-3,112 } \\
\text { trp1-1 ura3-1 can 1-100 yrs 1::HIS3 } \\
\text { yrr1::TRP1 pdr1::hisG pdr3::hisG }\end{array}$ & $\begin{array}{l}\text { Yeast Genetic } \\
\text { Resources Center, } \\
\text { Japan }\end{array}$ \\
\hline BY25929.1 & $\begin{array}{l}\text { MATa ade2-1 his3-11 leu2-3,112 } \\
\text { trp1-1 ura3-1 can 1-100 yrs 1::HIS3 } \\
\text { yrr1::TRP1 pdr1::hisG pdr3::hisG } \\
\text { erg3::IoxP-URA3-loxP }\end{array}$ & This study \\
\hline BY25929.2 & $\begin{array}{l}\text { MATa ade2-1 his3-11 leu2-3,112 } \\
\text { trp1-1 ura3-1 can1-100 yrs 1::HIS3 } \\
\text { yrr1::TRP1 pdr1::hisG pdr3::hisG } \\
\text { erg3:: IoxP }\end{array}$ & This study \\
\hline BY25929.3 & $\begin{array}{l}\text { MATa ade2-1 his3-11 leu2-3,112 } \\
\text { trp1-1 ura3-1 can1-100 yrs 1::HIS3 } \\
\text { yrr1::trp 1:: loxP -URA3- loxP } \\
\text { pdr1:: hisG pdr3::hisG erg3:: loxP }\end{array}$ & This study \\
\hline BY25929.4 & $\begin{array}{l}\text { MATa ade2-1 his3-11 leu2-3,112 } \\
\text { trp1-1 ura3-1 can 1-100 yrs 1::HIS3 } \\
\text { yrr1::trp 1:: loxP pdr1:: hisG } \\
\text { pdr3:: hisG erg3:: loxP }\end{array}$ & This study \\
\hline AS03 & $\begin{array}{l}\text { MATa ade2-1 his3-11 leu2- } \\
\text { 3,112 trp1-1 ura3-1 can 1-100 } \\
\text { yrs 1::HIS3 yrr1::trp1:: loxP } \\
\text { pdr1::hisG pdr3::hisG erg3::IoxP } \\
\text { nce103::IoxP-URA3- loxP }\end{array}$ & This study \\
\hline
\end{tabular}

(Thermo Fisher Scientific, USA) was used in the construction and transformation of recombinant plasmids. All clonings were performed using $E$. coli $\mathrm{DH} 5 \alpha$ grown at $37^{\circ} \mathrm{C}$ in Luria-Bertani medium (Titan Biotech LTD., India) containing $0.1 \mathrm{~g} \mathrm{~L}^{-1}$ ampicillin (T.P. Drug Laboratories, Thailand) (Sambrook et al. 1989). The S. cerevisiae strains used in this study are listed in Table 1. Yeast transformants were grown at $30^{\circ} \mathrm{C}$ in synthetic dextrose (SD) medium or synthetic raffinose (SR) medium $\left[6.7 \mathrm{~g} \mathrm{~L}^{-1}\right.$ yeast nitrogen base (YNB) without amino acids (Difco Laboratories, USA) and $20 \mathrm{~g} \mathrm{~L}^{-1}$ of either glucose or raffinose (Difco Laboratories, USA), respectively, containing only essential amino acids (Sigma Aldrich, USA)]. Uracil auxotrophic yeast strains were selected by 5 -fluoroorotic acid (5-FOA) medium containing $6.7 \mathrm{~g} \mathrm{~L}^{-1} \mathrm{YNB}$ with ammonium sulphate and without amino acids, $20 \mathrm{~g} \mathrm{~L}^{-1}$ glucose, $1 \mathrm{~g} \mathrm{~L}^{-1}$ 5-FOA (Zymo Research, USA) and essential amino acids as well as uracil. For the functional complementation, Western blot analysis and two step quantitative reverse transcription-polymerase chain 
Table 2 Plasmids used in this study

\begin{tabular}{|c|c|c|}
\hline Plasmid & Description & Reference \\
\hline $\begin{array}{l}\text { pAG414GAL (C Flag } \\
\text { hCAll) }\end{array}$ & $\begin{array}{l}\text { Amp } p^{R}, T R P 1, C E N, \\
\text { hCAll_Flag }\end{array}$ & Panthan (2011) \\
\hline pRS414 & $A m p^{R}, U R A 3, C E N$ & Addgene, USA \\
\hline pGAL1.1_hCAll & $\begin{array}{l}\text { Amp } p^{R}, \text { URA3, CEN, } P_{\text {GALI.1' }} \\
\text { hCAll_Flag }\end{array}$ & This study \\
\hline pGAL1.2_hCAll & $\begin{array}{l}\text { Amp } p^{R}, \text { URA3, CEN, } P_{\text {GALI.2' }} \\
\text { hCAll_Flag }\end{array}$ & This study \\
\hline pGAL1.3_hCAll & $\begin{array}{l}\text { Amp } p^{R}, \text { URA3, CEN, } P_{\text {GALI.3' }} \\
\text { hCAll_Flag }\end{array}$ & This study \\
\hline pGAL1.4_hCAll & $\begin{array}{l}\text { Amp } p^{R}, \text { URA3, CEN, } P_{\text {GAL1.4t }} \\
\text { hCAll_Flag }\end{array}$ & This study \\
\hline pUG72 & $A m P^{R}$, IOXP-URA3-IOXP & Euroscarf, Germany \\
\hline
\end{tabular}

reaction (qRT-PCR) experiments, the yeast transformants were induced for hCAII expression by cultivation in synthetic galactose (SG) medium $\left(6.7 \mathrm{~g} \mathrm{~L}^{-1} \mathrm{YNB}\right.$ without amino acids, $10 \mathrm{~g} \mathrm{~L}^{-1}$ raffinose, $20 \mathrm{~g} \mathrm{~L}^{-1}$ galactose; Difco, USA) containing $0.2 \mathrm{~g} \mathrm{~L}^{-1}$ adenine, $1 \mathrm{~g} \mathrm{~L}^{-1}$ leucine and $0.1 \mathrm{~g} \mathrm{~L}^{-1}$ histidine (SG+Ade $\left.+\mathrm{Leu}+\mathrm{His}\right)$. The $\Delta$ nce103 strain was grown under the high- $\mathrm{CO}_{2}$ condition (5\% (v/v) $\mathrm{CO}_{2}$ ) using an AnaeroPack (Mitsubishi Gas Chemical, Japan).

\section{Chemicals}

Acetazolamide (AZA) and FK506 were purchased from Sigma Aldrich, USA. Avicennin was a gift from Dr. Warinthorn Chavasiri, Department of Chemistry, Faculty of Science, Chulalongkorn University, Thailand.

\section{Plasmid construction}

All plasmids used in this study are shown in Table 2. The hCAII cDNA was obtained from Krungkrai et al. (2005). A full-length GAL1 promoter (nucleotide positions 1-451) fused with the Flag epitope tag at the C-terminal of $h C A I I$ (c-Flag $h C A I I$ ) was obtained by PCR amplification from the pAG414GAL (c-Flag $h C A I I$ ) vector (Panthan 2011) using the oligonucleotide primers pGAL1.4_hCAII Fw and NotI_hCAII Rv (Table 3). Each PCR reaction was performed in a total volume of $50 \mu \mathrm{L}$ according to the manufacturer's protocol of KODPlus-Neo (Toyobo, Japan) containing $5 \mu \mathrm{L}$ of $10 \times$ buffer for KOD-Plus-Neo, $5 \mu \mathrm{L}$ of $2 \mathrm{mM}$ dNTP, $3 \mu \mathrm{L}$ of $25 \mathrm{mM}$ $\mathrm{MgSO}_{4}, 0.75-1.5 \mu \mathrm{L}$ of $10 \mu \mathrm{M}$ of each primer, $1 \mu \mathrm{L}$ of KOD-Plus- Neo and 1-2 $\mu \mathrm{L}$ of DNA template. The reaction was performed for 35 cycles of $95{ }^{\circ} \mathrm{C}$ for $30 \mathrm{~s}, 62{ }^{\circ} \mathrm{C}$ for $30 \mathrm{~s}$ and $72{ }^{\circ} \mathrm{C}$ for $90 \mathrm{~s}$. Purified PCR products were ligated into pGEM-T easy (Promega, USA) and then subcloned via a unique NotI site into pRS414 (Addgene, USA), a CEN4-ARS1 plasmid with TRP1 selection marker, to yield the designated pGAL1.4_hCAII plasmid.
To modulate the transcription level of hCAII under the control of the GAL1 promoter, modification of the number of Gal4 binding sites (Cottier et al. 2006; Giniger et al. 1985; Hong et al. 2008; Liang et al. 1996; Marmorstein et al. 1992) was performed by PCR amplification from the pAG414GAL (c-Flag $h C A I I$ ) plasmid using the desired forward primer (one of pGAL1.3_hCAII Fw, pGAL1.2_ hCAII Fw or pGAL1.1_hCAII Fw) with the reverse primer NotI_hCAII Rv (Table 3) to amplify a GAL1 promoter with either three, two or one Gal4 binding site domains, respectively. All PCR reactions were performed as described above. The resulting plasmids with three, two and one Gal4 binding sites were designated as pGAL1.3_hCAII, pGAL1.2_hCAII and pGAL1.1_hCAII, respectively.

\section{Gene disruption}

A PCR-based gene disruption method (Gueldener et al. 2002) was employed in the yeast strain W303-1A and BY25929 background (Table 1). A disruption cassette, containing the loxP-URA3-loxP sequence of pUG72 (EUROSCARF, Germany) flanked at both sides with a short homology sequence of $40 \mathrm{bp}$ at the $5^{\prime}$ and $3^{\prime}$ termini of the target gene, was amplified by PCR using oligonucleotide primers (Table 3 ) as follows. The disruption cassette loxP-URA3-loxP for the ERG3 gene (Accession No. M64989.1) was amplified using oligonucleotide primers D-ERG3_Fw and D-ERG3_Rv, whereas the other disruption cassettes were amplified using the primer pairs D-TRP1_Fw and D-TRP1_Rv for TRP1 (Accession No. NM_001180315.3) and D-NCE103_Fw and D-NCE103_ Rv for NCE103 (Accession No. NM_001182875.3).

The respective amplified disruption cassette was transformed into the yeast cells and successful disruptants were confirmed by PCR using the gene-specific oligonucleotide primers (Table 3 ).

\section{Yeast transformation}

Yeast cells were transformed by the lithium acetate method with $1 \mu \mathrm{g}$ plasmid or $5 \mu \mathrm{g}$ DNA fragment, respectively (Gietz et al. 1995). In addition, $50 \mu \mathrm{g}$ of carrier DNA, deoxyribonucleic acid sodium salt from salmon testes (Sigma Aldrich, USA), was added to enhance the transformation efficiency (Gietz et al. 1995).

\section{Yeast complementation experiment}

Complementation of the $\Delta n c e 103$ yeast strain was performed as follows. The exponential growth phase of the yeast transformants in $3 \mathrm{~mL} \mathrm{SR}+$ Ade $+\mathrm{Leu}+\mathrm{His}$ medium was diluted to a final $10^{6}-10^{3}$ cells $\mathrm{mL}^{-1}$ and $5 \mu \mathrm{L}$ of each serially diluted culture were spotted onto the 
Table 3 Oligonucleotide primers used in this study

\begin{tabular}{|c|c|}
\hline Primer name & Primer sequence $\left(5^{\prime}-3^{\prime}\right)$ \\
\hline \multicolumn{2}{|c|}{ A. Primers used in the PCR amplified disruption cassettes for gene disruption } \\
\hline D-ERG3_FW & $\begin{array}{l}\text { ATTTCTATCTTTCTTATCAATTCGTTTTTTCATTCACTTGTCAGCTGAAGCTTCGTA } \\
\text { CGC }\end{array}$ \\
\hline D-ERG3_RV & $\begin{array}{l}\text { TCTTGAACGTGAAAGAAAGAAAAAAGATGAGACAAACAAGATAGGCCACTA } \\
\text { GTGGATCTG }\end{array}$ \\
\hline D-NCE103_FW & TACAAATTTCAATTATTACACATCAGACAGCTGAAGCTTCGTACGC \\
\hline D-NCE103_RV & $\begin{array}{l}\text { CCCCGTCTACTTTGTAAATGTCTTTCTATTTCAATGAATGGTAGGCCACTAGTG } \\
\text { GATCTG }\end{array}$ \\
\hline D-TRP1_FW & $\begin{array}{l}\text { GTCTGTTATTAATTTCACAGGTAGTTCTGGTCCATTGGTGACAGCTGAAGCTTC } \\
\text { GTACGC }\end{array}$ \\
\hline D-TRP1_RV & $\begin{array}{l}\text { CTATTTCTTAGCATTTTTGACGAAATTTGCTATTTTGTGCATAGGCCACTAGTG } \\
\text { GATCTG }\end{array}$ \\
\hline \multicolumn{2}{|c|}{ B. Primers used for the confirmation of successful gene disruption in yeast chromosome } \\
\hline C-ERG3_Fw1 & CGAAACGACGCCTTTTGTTGCGATTGTCG \\
\hline C-ERG3_Rv1 & ATTTGTGTGCTTCTCTTGACGTTCGTTCG \\
\hline C-ERG3_FW2 & TTCAACAAGTTTCAATAGCTCATCAGTCG \\
\hline C-ERG3_Rv2 & GAAATCTTGGGCATTTTAAAGCTTCCAGC \\
\hline C-NCE103_FW1 & GTCACCATGACGCTTATCAAGCC \\
\hline C-NCE103_Rv1 & ATCGGGCGTTTACCGTATCGC \\
\hline C-NCE103_FW2 & CTACACCTGGGGTCATGATTAGCC \\
\hline C-NCE103_Rv2 & GACATTTGCTGGATCACAGACCG \\
\hline \multicolumn{2}{|c|}{ C. Primers used in the PCR amplification of the GAL1 promoter derivative fused with $h C A l l$} \\
\hline pGAL1.4 FW & TACAGCTAAGACTACAAAACGGATTAGAAGCCGCCG \\
\hline pGAL1.3 FW & TACAGCTAAGACTACAAACCGAGCGGGCGACAGCCC \\
\hline pGAL1.2 FW & TACAGCTAAGACTACAAACCGACGGAAGACTCTCCTC \\
\hline pGAL1.1 FW & TACAGCTAAGACTACAAAGCAGATGTGCCTCGCGCC \\
\hline Notl_hCAll Rv & TTTTCCTTTTGGGGCCGCTTTTTTTCCTTTTATTTATCATCATCATCTTTTG \\
\hline
\end{tabular}

surface of SG + Ade + Leu + His agar medium. The plates were incubated at $30{ }^{\circ} \mathrm{C}$ for 3-4 days under either the high- or the low- $\mathrm{CO}_{2}$ condition.

\section{Two step quantitative reverse transcription-polymerase chain reaction (qRT-PCR)}

The recombinant strains were cultured in $\mathrm{SG}+\mathrm{Ade}+\mathrm{Leu}+\mathrm{His}$ medium and then total RNA was extracted using the Masterpure yeast RNA purification kit (Epicentre, USA), as recommended by the manufacturer. For the first stage RT-PCR, aliquots of total RNA $(1 \mu \mathrm{g})$ were converted into complementary DNA (cDNA) using RevertAid Reverse Transcriptase (Thermo Fisher Scientific, USA) and the respective gene-specific primers (Table 3 ). All second stage qRTPCR were run using the SsoAdvanced Universal SYBR Green Supermix (Bio-Rad, USA). The plates containing the qRT-PCR mix were transferred to the CFX Connect Real-Time PCR Detection System (Bio-Rad, USA) and thermal cycled at $95{ }^{\circ} \mathrm{C}$ for $3 \mathrm{~min}$ followed by 35 cycles of $95^{\circ} \mathrm{C}$ for $30 \mathrm{~s}, 50{ }^{\circ} \mathrm{C}$ for $30 \mathrm{~s}$ and $72{ }^{\circ} \mathrm{C}$ for $30 \mathrm{~s}$.
Relative gene expression levels were calculated using the $2^{-\Delta \Delta C \mathrm{CT}}$ method (Livak and Schmittgen 2001).

\section{Western blotting analysis}

Yeast cells cultured in the inducible $(\mathrm{SG}+\mathrm{Ade}+\mathrm{Leu}+\mathrm{His})$ medium were lysed by vortexing with acid-washed glass beads of 0.45-0.55 diameter (Sigma Aldrich, USA) in sodium dodecyl sulfate (SDS)sample buffer and subjected to $12 \%$ SDS-polyacrylamide gel electrophoresis (SDS-PAGE) and Western blotting analysis using the rabbit anti-Flag (DYKDDDDK tag) primary antibody (Cell Signaling, USA) and horseradish peroxidase conjugated donkey anti-rabbit IgG as the secondary antibody (Cell Signaling, USA). Protein signals were detected by Pierce ${ }^{\mathrm{TM}}$ ECL Western Blotting Substrate (Thermo Fisher Scientific, USA).

\section{Resazurin microtiter plate assay}

The REMA was performed in 96-well plates as follows. Briefly, $1 \mu \mathrm{L}$ of test compound was dissolved in $80 \mu \mathrm{L}$ of $\mathrm{SR}+$ Ade $+\mathrm{Leu}+\mathrm{His}$ medium to the 
desired concentration and aliquoted into each well. The AS03(pGAL1.1_hCAII) yeast cells cultivated in $\mathrm{SR}+$ Ade + Leu + His medium were then added into each well of the 96-well plate at the appropriate cell density for $10 \mu \mathrm{L}$. The test plate was incubated at room temperature for $30 \mathrm{~min}$ and then $10 \mu \mathrm{L}$ of $20 \%(\mathrm{w} / \mathrm{v})$ galactose was added into each well and incubated at $30{ }^{\circ} \mathrm{C}$ under an ambient atmosphere $\left(\right.$ low $\mathrm{CO}_{2}$ ) or $5 \%$ (v/v) $\mathrm{CO}_{2}$ condition (high $\mathrm{CO}_{2}$ ) for the appropriate incubation time. A stock solution of $0.1 \mathrm{mg} \mathrm{mL}^{-1}$ resazurin sodium salt (Sigma Aldrich, USA) prepared in distilled water was added to each well to a final concentration of $0.03 \mathrm{mg} \mathrm{mL}^{-1}$ and further incubated at $30{ }^{\circ} \mathrm{C}$ in the dark until the color of the wells without the test compound changed from blue to pink, which indicated the growth of yeast cells. The minimal effective dose was defined as the lowest concentration of the drug that could inhibit the growth of yeast cells and so prevent the color change of resazurin. In addition to the color observation in the test wells, the ratio of the optical densities between resorufin $\left(\mathrm{OD}_{572}\right)$ and resazurin $\left(\mathrm{OD}_{600}\right)$ was evaluated to determine the level of reduction of resazurin to resorufin. Measurement of the yeast culture turbidity at $660 \mathrm{~nm}\left(\mathrm{OD}_{660}\right)$ (Amberg et al. 2005) was also performed before the addition of resazurin.

\section{Statistical analysis}

Statistical analysis was performed using the GraphPad Prism 5.01 package (GraphPad Software INC., USA) with one-way analysis of variance, followed by the Dunnett post-test. Each determination was performed in triplicate. Statistical significance was accepted at the $p<0.05$ level.

\section{Results}

Construction of a drug-sensitive derivative of the nce 103 null mutant of $S$. cerevisiae expressing various levels of hCAll from modified GAL1-promoter-based expression cassettes

The yeast $S$. cerevisiae is generally highly tolerant to various drugs, which poses a serious obstacle for their use in a yeast-based in vivo drug assay.The yeast strain BY25929 (obtained from the Yeast Genetic Resources Center, Japan; Table 1), was modified to attenuate the general permeability barriers for drugs by disruption of the $E R G 3$ gene, which is involved in the biosynthesis of ergosterol, a major component of the cell membrane (Hemmi et al. 1995). In addition, the NCE103 gene, which codes for $\mathrm{CA}$, was also disrupted. The drug-sensitive derivative of the nce103 null-mutant strain so obtained was designated as the AS03 strain (Table 1).
The AS03 strain was further engineered to express hCAII at various levels. For this purpose, we used the GAL1 promoter containing four copies of the Gal4binding site to construct a series of modified promoters containing either four, three, two or one copy(ies) of the Gal4-binding site, as previously described (Cottier et al. 2006; Liang et al. 1996), and these were designated pGAL1.4_hCAII, pGAL1.3_hCAII, pGAL1.2_hCAII or pGAL1.1_hCAII, respectively. The drug-sensitive nce103 null strain (AS03) was then separately transformed with each of these hCAII expression plasmids.

The expression levels of hCAII in the transformants were compared by multiple methods. The functional complementation of the growth defect by the exogenous hCAII gene was examined by growth of the transformants under the control of GAL1 promoter under the low- $\mathrm{CO}_{2}$ condition. All the transformants harboring the hCAII expression constructs could grow similarly well, while those with the empty vector showed a severe growth defect (data not shown).

We next compared the hCAII protein levels of the transformants by Western blot analysis. Protein extracts of the yeast transformants with the plasmid containing an expression construct for the Flag-epitope-tagged hCAII at the C-terminus showed increasing levels of the $29 \mathrm{kDa}$ Flag-hCAII band with the increasing number of the Gal4-binding sites located in the modified GAL1 promoter of the expression constructs (Fig. 1a). Setting the relative protein levels of the transformants with four Gal4-binding sites as $100 \%$, the levels in the other transformants were $82 \%, 62 \%$ and $39 \%$ for three, two and one Gal4-binding sites, respectively.

We further compared the mRNA levels of the transformants by two-step qRT-PCR (Fig. 1b). The obtained hCAII mRNA levels were consistent with the hCAII protein levels.

Next, we compared the sensitivity to AZA, a known CAI including against hCAII (Supuran 2008), of three different yeast strains with deletions of various genes responsible for the general drug resistance of the cells that rely on the exogenous hCAII under the low- $\mathrm{CO}_{2}$ condition. Specifically, the strains AS01 ( $\Delta$ nce103), AS02 $(\Delta n c e 103 \Delta e r g 3)$ and AS03 $(\Delta n c e 103 \Delta e r g 3 \Delta p d r 1 \Delta p d r 3$ $\Delta y r r 1$ ) (Table 1) harboring the pGAL1.1_hCAII expression plasmid were constructed and subjected to the drug sensitivity assay on agar plates containing various concentrations of AZA and measuring their growth under the low- $\mathrm{CO}_{2}$ condition (spot-test assay). The result revealed that the minimal effective dose of AZA for the transformants of the AS03, AS02 and AS01 strains were $12.5,25$ and $50 \mu \mathrm{M}$, respectively (Fig. 2).

To evaluate the most appropriate expression level of hCAII to be used in the indicator cells for the 


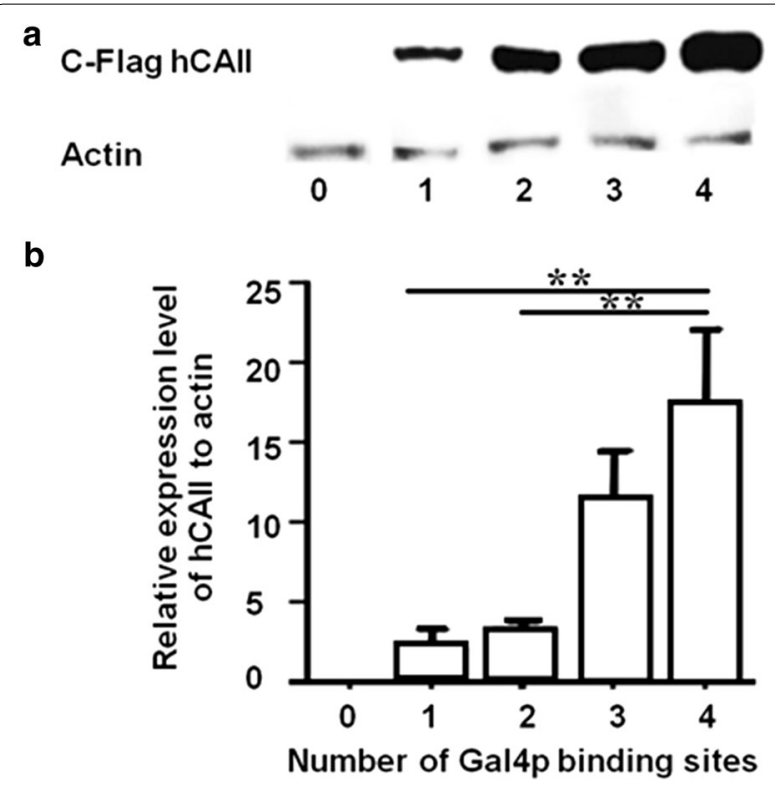

Fig. 1 Expression level of hCAll under the control of variously modified GAL1 promoters. The drug-sensitive AS03 yeast strain harboring either the empty pRS414 vector or one of the GAL1 promoter derivatives containing either one, two, three or four copies of the Gal4-binding sites (pGAL1.1_hCAll, pGAL1.2_hCAll, pGAL1.3_ hCAll or pGAL1.4_hCAll, respectively) was cultivated under a GAL1-induced condition for $24 \mathrm{~h}$ before harvesting. a Protein extracts were prepared and subjected to Western blot analysis using anti-Flag to detect hCAll and anti- $\beta$-actin to detect $\beta$-actin. Blots shown are representative of those seen from three independent repeats. b Total RNA was prepared and converted to CDNA prior to the GRT-PCR analysis of the hCAll mRNA expression level. Data are expressed as the relative level of hCAll mRNA to actin mRNA and shown as the mean expression level, \pm 1 SD, and derived from three independent repeats. **Significant difference at $\mathrm{p}<0.01$ compared to that of the transformant with the pGAL1.4_hCAll plasmid

yeast-based assay, the AS03 strain was transformed with the different hCAII expression plasmids and then subjected to the spot test assay on plates containing various concentrations of AZA $(0,3.13,6.25$ and 12.5 $\mu \mathrm{M})$ under the low- $\mathrm{CO}_{2}$ condition. The result showed that the AS03(pGAL1.1_hCAII) transformant which expressed the lowest level of hCAII was the most sensitive strain. It was, therefore, selected for indicator cells in the yeast-based inhibitor assay.

\section{Setting up a resazurin-yeast-based high throughput screening assay}

We next attempted to establish the assay conditions by which hCAII inhibitors could be identified using the AS03(pGAL1.1_hCAII) transformant as the assay cells under the low- $\mathrm{CO}_{2}$ condition.
Resazurin is an oxidation-reduction dye that changes color from blue (resazurin) to pink (resorufin) and further to colorless (hydroresorufin) after reduction by living cells (Rampersad 2012). We chose to examine the viability of the indicator cells in liquid culture having resazurin as an indicator dye in a 96 well-plate format.

The AS03(pGAL1.1_hCAII) indicator cells were cultivated in the SG+Ade+Leu+His medium for the induced expression of hCAII under the low- $\mathrm{CO}_{2}$ condition in the absence or presence of AZA as a CAI (Figs. 4 and 5).

To optimize the initial density of the assay cells, we compared the effect of the cell density on the color reaction by varying the initial seeding density from 1 to $100 \times 10^{4}$ cells $\mathrm{mL}^{-1}$. As shown in Fig. 4, the optimal initial cell densities were found to be between 0.5 and $1 \times 10^{5}$ cells $\mathrm{mL}^{-1}$. The $\mathrm{OD}_{572} / \mathrm{OD}_{600}$ ratio in the wells containing AZA was approximately half of that in the negative control well. However, when higher cell densities (between 0.5 and $1 \times 10^{6}$ cells $\mathrm{mL}^{-1}$ ) were used, the $\mathrm{OD}_{572} / \mathrm{OD}_{600}$ ratio in the wells containing AZA was higher than that in the negative control well. In contrast, when a lower cell density $\left(1 \times 10^{4}\right.$ cells $\left.\mathrm{mL}^{-1}\right)$ than the optimal one was used, the ratios in the wells with or without AZA did not show any significant difference (Fig. 4a). The $\mathrm{OD}_{572} / \mathrm{OD}_{600}$ ratios (Fig. 4a) were consistent with the visually observed color changes (Fig. 4b).

We further investigated various other parameters of the assay, such as the incubation time between the addition of the indicator cells and the test sample, and the incubation time with resazurin before determination of the $\mathrm{OD}_{572} / \mathrm{OD}_{600}$ ratio (data not shown). The standard assay conditions were finally established as follows. The indicator cells were cultivated in the presence of the test samples for $24 \mathrm{~h}$ at $30^{\circ} \mathrm{C}$, and then incubated with resazurin for $4 \mathrm{~h}$ before assaying the $\mathrm{OD}_{572} / \mathrm{OD}_{600}$ ratio.

\section{Evaluation of the yeast-based REMA system}

To evaluate the yeast-based assay conditions, the dependency of the color reaction on the dose of AZA was examined using serial dilutions of AZA ranging from 0.02 to $25 \mu \mathrm{M}$ in the SG+Ade+Leu + His medium containing the assay cells at $1 \times 10^{5}$ cells $\mathrm{mL}^{-1}$. The plates were incubated under the low- and high- $\mathrm{CO}_{2}$ conditions to determine the inhibitory effect on the hCAII and the cytotoxicity of AZA, respectively. We found that AZA significantly inhibited hCAII at a dose of $0.31 \mu \mathrm{M}$ but no cytotoxicity was detected even at the highest concentration of AZA tested $(25 \mu \mathrm{M})$ under the high $\mathrm{CO}_{2}$-condition (Fig. 5a, b). The results determined by the $\mathrm{OD}_{572} / \mathrm{OD}_{600}$ ratio (Fig. $5 \mathrm{~b}$ ) were consistent with the visual color-changes observed (Fig. 5c). 


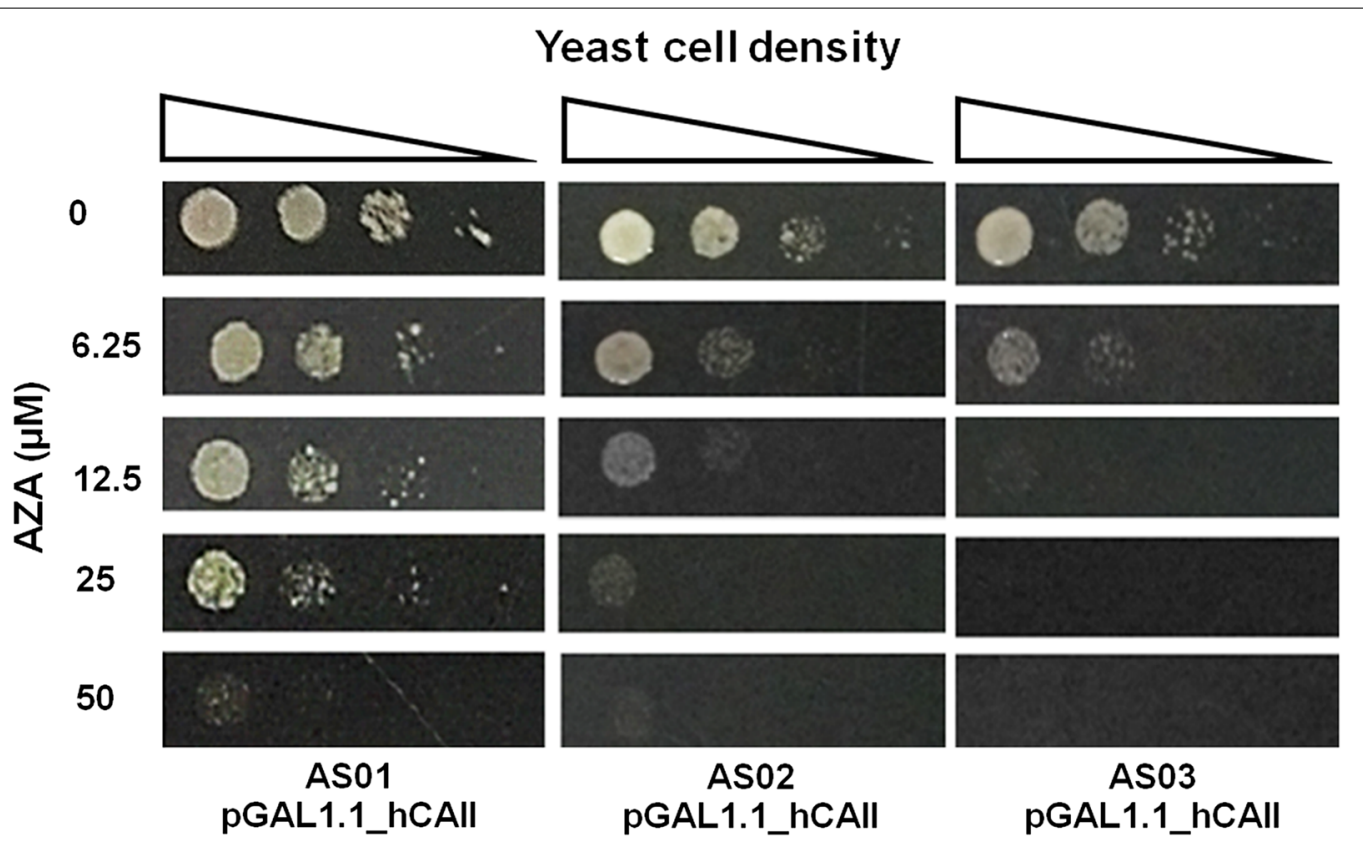

Fig. 2 Comparision of the drug-sensitivity phenotype of various NCE103 null mutant yeast strains. The AS01, ASO2 and AS03 cells harboring the pGAL1.1_hCAll plasmid at concentrations of $10^{6}, 10^{5}, 10^{4}$ and $10^{3}$ cells $\mathrm{mL}^{-1}$ were spotted onto the surface of SG + Ade + Leu + His plates containing either $0,6.25,12.5$ or $50 \mu \mathrm{M}$ AZA and incubated at $30^{\circ} \mathrm{C}$ for $3-4$ days under a low $\mathrm{CO}_{2}$ condition. Images shown are representative from three independent repeats

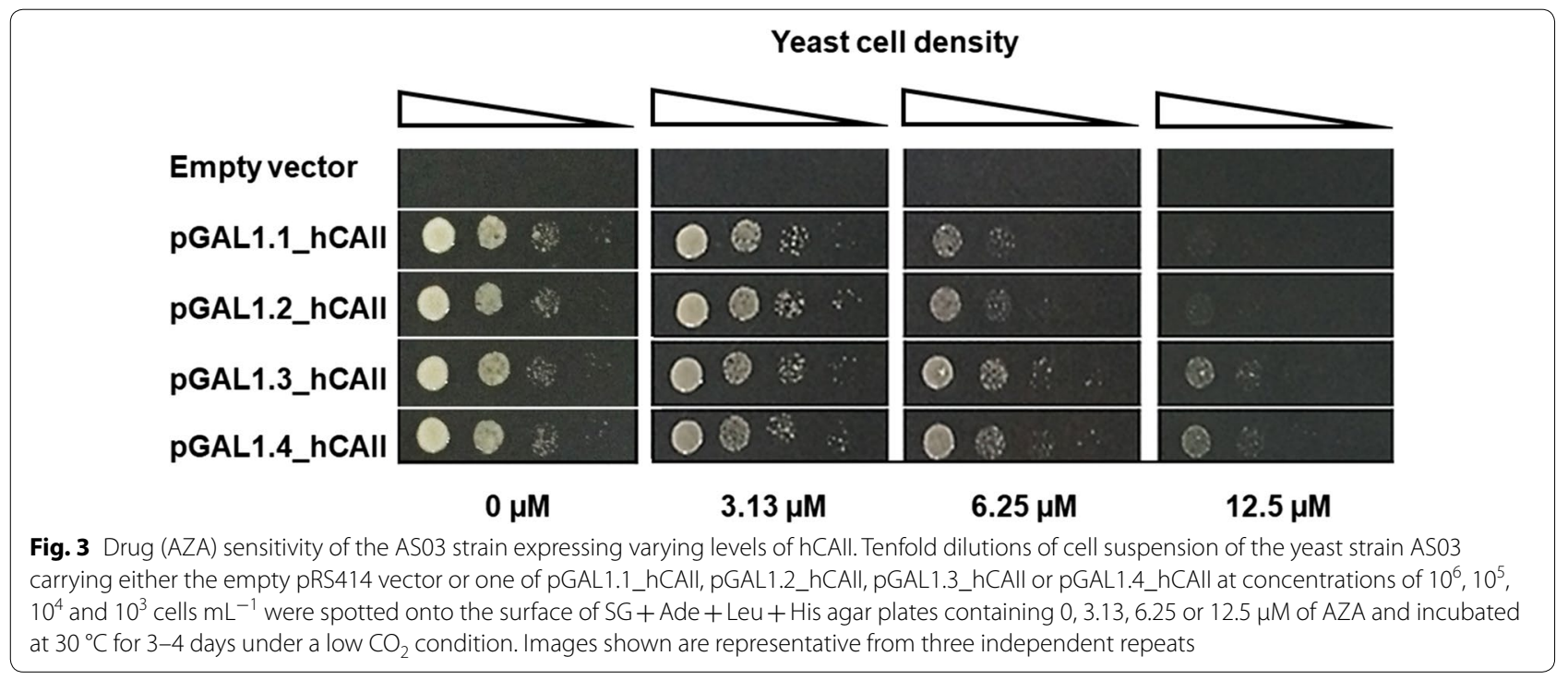

Comparison of the cell metabolism by the REMA method with that determined by the $\mathrm{OD}_{660}$ values revealed that the $\mathrm{OD}_{660}$ values showed consistent results with the $\mathrm{OD}_{572} / \mathrm{OD}_{600}$ ratio (Fig. $5 \mathrm{a}, \mathrm{b}$ ), and so could be used as a surrogate indicator of cell growth.

To further evaluate the specificity of the assay system, we compared the effect of AZA with those of avicennin, a CA isozyme IX inhibitor (Davis et al. 2013) and a FK506, a calcineurin inhibitor (Breuder et al. 1994; Liu et al. 1991; Rusnak and Mertz 2000; Shitamukai et al. 2000; Sugiura et al. 2001). The results showed that avicennin at $500 \mu \mathrm{M}$ (its maximum solubility) showed only a weak inhibitory effect and FK506 up to $10 \mu \mathrm{M}$ (its maximum solubility) showed no detectable inhibitory 


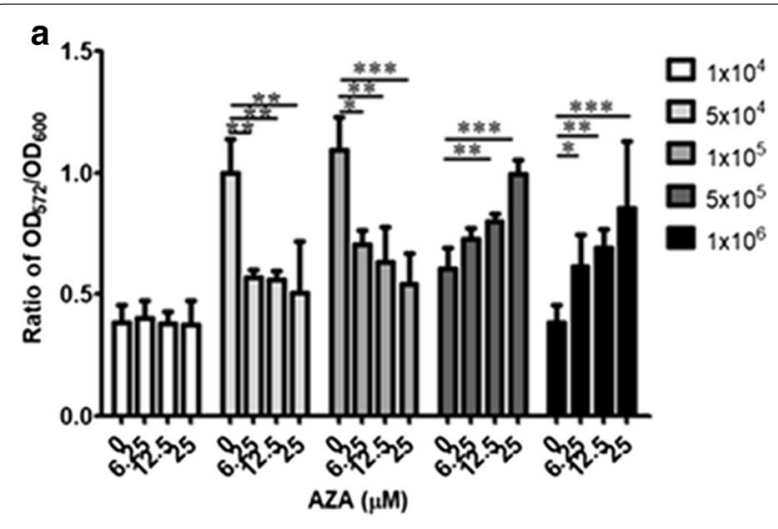

b

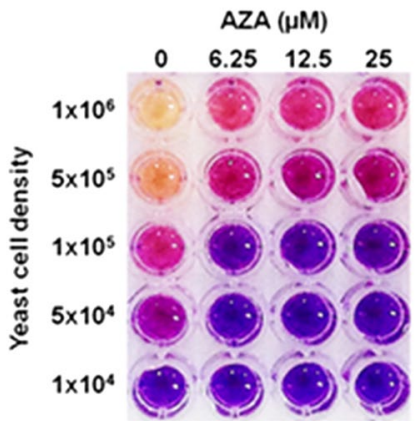

Fig. 4 Optimization of the initial cell concentration using the REMA. A suspension of the yeast strain AS03(pGAL1.1_hCAll) at varying final concentrations of $1 \times 10^{6}, 5 \times 10^{5}, 1 \times 10^{5}, 5 \times 10^{4}$ and $1 \times 10^{4}$ cells $\mathrm{mL}^{-1}$ in $100 \mu \mathrm{L}$ of SG + Ade + Leu + His medium were added to each well of a 96-well plate with varying concentrations of AZA $(0,6.25,12.5$ and $25 \mu \mathrm{M})$. The plates were incubated at $30^{\circ} \mathrm{C}$ for $24 \mathrm{~h}$ whereupon resazurin was added and $4 \mathrm{~h}$ later the $\mathrm{OD}_{572}$ and $\mathrm{OD}_{600}$ values were measured and expressed as a the $\mathrm{OD}_{572} / \mathrm{OD}_{600}$ ratio and b visual observation. Data are shown as $\mathbf{a}$ the mean \pm 1 SD derived from three independent repeats, where ${ }^{*},{ }^{* *}$ and ${ }^{* * *}$ represent a significant difference at $p<0.05, p<0.01$ and $p<0.001$ levels, respectively, compared to that of the untreated control group, and $\mathbf{b}$ representative image of three independent repeats

activity (Fig. 5c), indicating the high specificity of our assay system.

\section{Discussion}

In this study, a novel yeast-based screening system for the detection of compounds that could inhibit the function of hCAII in vivo was successfully established using a high drug sensitive $n c e 103$ null yeast mutant expressing hCAII as indicator cells. S. cerevisiae is highly tolerant of various drugs, due to the presence of ATP-binding cassette $(\mathrm{ABC})$ transporter genes resulting in the poor permeability of these drugs through the yeast cell surface (Piecuch and Oblak 2014). Therefore, in this study the yeast strain BY25929 that has been disrupted for the genes encoding transcription activation factors of the ABC transporter genes (PDR1, PDR3 and YRR1) and the ABC gene YOR1 (Miyamoto et al. 2002), was further modified to attenuate the general permeability barriers for drugs by disruption of the ERG3 gene, which encodes the C- 6 desaturase of the ergosterol biosynthesis pathway (Hemmi et al. 1995). Then, the NCE103 gene was further deleted along with the drug resistance genes to obtain a higher drug sensitive nce 103 null yeast strain designated as the AS03 strain. The $\Delta$ nce 103 strain deprived of its own CA can grow under a high (5\%)-but not a low (ambient)- $\mathrm{CO}_{2}$ condition due to the difference in the availability of bicarbonate ions that are essential for cellular anaplerotic reactions (Aguilera et al. 2005). However, its growth defect phenotype when cultivated under a low- $\mathrm{CO}_{2}$ condition could be restored by overexpression of hCAII (Clark et al. 2004), or by only a low expression level of hCAII (Fig. 2).

The GAL1 promoter was used to control the expression level of hCAII in the yeast transformants. GAL1 is a strong-inducible promoter that strongly expresses when galactose, but not glucose, is present in the medium. The promoter contains the $\mathrm{UAS}_{\mathrm{GAL}} 17$-mer sites CGG-N ${ }_{11^{-}}$ CCG (Giniger et al. 1985) in four domains (Gal4 binding sites) that are recognized by the Gal4p homodimer transcription activator (Hong et al. 2008; Marmorstein et al. 1992). Cottier et al. (2006) reported that modifications in the number and type of Gal4 binding sites modulates the level of transcription of the HCMV protease gene, with $100 \%, 71 \%, 46 \%$ and $16 \%$ protein production levels, relative to the original GAL1 promoter, with four, three, two and one Gal4 binding sites, respectively. In agreement with the above observation, our Western blot analysis and qRT-PCR results showed differential expression of hCAII in direct proportion with the number of Gal4 binding sites in the GAL1 promoter of the expression

(See figure on next page.)

Fig. 5 Determination of the minimal effective dose of the tested compounds. Serial dilutions of either AZA ( $0-25 \mu M)$, avicennin ( $0-500 \mu M)$ or FK506 (0-10 $\mu \mathrm{M}$ ) were added in wells of a 96-well plate containing $0.5 \times 10^{5}$ cells $\mathrm{mL}^{-1}$ of AS03(pGAL1.1_hCAll) cells and incubated at $30^{\circ} \mathrm{C}$ under a high- or low- $\mathrm{CO}_{2}$ condition. a The growth of the yeast strain treated with $\mathrm{AZA}$ was determined by the $\mathrm{OD}_{660}$ value prior to adding resazurin into each well. $\mathbf{b}$ Then, after $4 \mathrm{~h}$, the $\mathrm{OD}_{572}$ and $\mathrm{OD}_{600}$ values were measured and expressed as the $\mathrm{OD}_{572} / \mathrm{OD}_{600}$ ratio. $\mathbf{c}$ The colorimetric results of the assay for three tested compounds were also observed visually. Data are shown as $(\mathbf{a}, \mathbf{b})$ the mean \pm 1 SD derived from three independent repeats, where $*^{* *}$ and ${ }^{* * *}$ represent a significant difference at $p<0.05, p<0.01$ and $p<0.001$ levels, respectively, compared to that of the untreated control group, and $\mathbf{c}$ a representative image of three independent repeats 

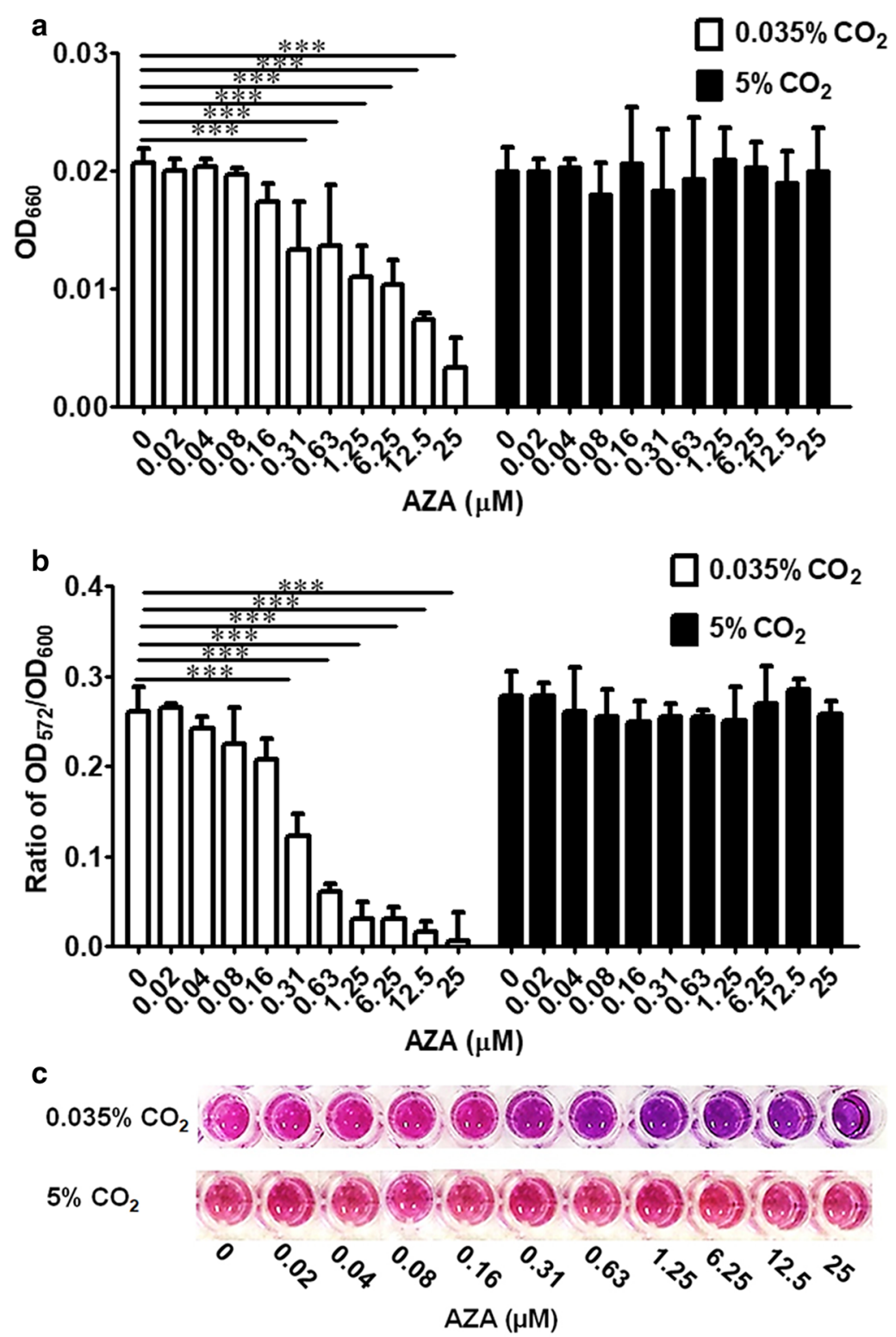

$0.035 \% \mathrm{co}_{2} \mathrm{O} \odot \odot \odot \bigcirc \bigcirc \bigcirc 0$

$5 \% \mathrm{CO}_{2}$

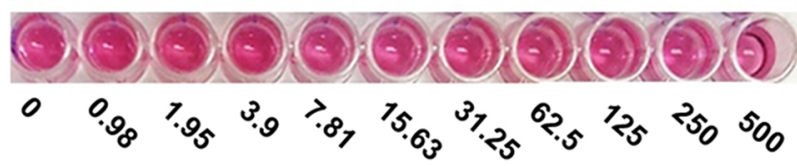

Avicennin $(\mu \mathrm{M})$

$0.035 \% \mathrm{CO}_{2}$

$5 \% \mathrm{CO}_{2}$

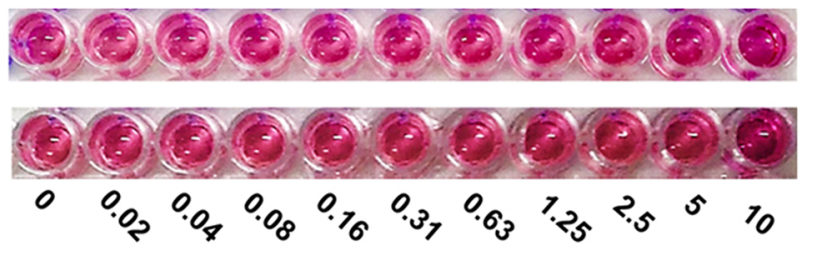

FK506 ( $\mu \mathrm{M})$ 
construct as $100 \%, 82 \%, 62 \%$ and $39 \%$ for four, three, two and one Gal4 binding site(s), respectively (Fig. 1).

Taken together, the results of Figs. 1, 2 (at $0 \mu \mathrm{M}$ AZA) and 3 (at $0 \mu \mathrm{M}$ AZA) revealed that even the lowest level of hCAII (expressed from the promoter containing a single Gal4-binding site) was sufficient to complement the growth defect of the nce103 null mutant under the low$\mathrm{CO}_{2}$ condition.

Thus, using this transformant with the lowest expression level of hCAII (pGAL1.1_hCAII), we compared the sensitivity to AZA with three different yeast strains with deletions of various genes responsible for the general drug resistance of the cells under the low- $\mathrm{CO}_{2}$ condition. The spot test assay for AZA sensitivity of the three different strains of nce103 null mutant background (AS01, AS02 and AS03; Table 1) revealed the strain showing the highest sensitivity to AZA was AS03(pGAL1.1_hCAII), followed by AS02(pGAL1.1_hCAII) and AS01(pGAL1.1_ hCAII), respectively (Fig. 2). These results confirmed the high AZA sensitivity of the chosen indicator cells for our yeast-based assay and showed that CAIs that are effective against hCAII can be assayed for by monitoring the growth of these yeast strains (AS03, AS02 and AS01) relying on hCAII under the low- $\mathrm{CO}_{2}$ condition.

We chose the AS03 strain, as the most drug-sensitive strain, to examine the effect of the expressed levels of hCAII on the sensitivity to AZA. As expected, the degree of AZA resistance was positively correlated with the hCAII expression level (Fig. 3). Based on these data, the AS03(pGAL1.1_hCAII) transformant, which expressed the lowest level of hCAII (Fig. 1) and was the most sensitive strain, was selected as the indicator cells in the yeastbased inhibitor assay.

For the operational convenience of a HTS assay for a large number of samples using this yeast-based in vivo assay, we chose to examine the viability of the assay cells in liquid culture with resazurin as an indicator dye using a 96 well-plate format.

The principle of this yeast-based assay was that if tested compounds inhibit hCAII activity, then the nce103 null mutant indicator cells would not be able to grow under the low $\mathrm{CO}_{2}$-condition but would grow under the high$\mathrm{CO}_{2}$ condition if they were otherwise not cytotoxic to the yeast. Although the $\mathrm{OD}_{660}$ measurement provided an easy and efficient way to quantify yeast growth over time, metabolic indicators of the cell density, based on the metabolism-dependent reduction of colorimetric dyes, provide an alternative measurement of yeast cell density as well as providing an indicator of yeast vitality (Goughenour et al. 2015). Here, we used the colorimetric indicator resazurin that can also be used as a more objective qualitative indicator. Although the use of resazurin as indicator dye for cell viability has several advantages, care must be taken in setting up the REMA to get a correlation between the $\mathrm{OD}_{572} / \mathrm{OD}_{600}$ ratio and cell turbidity $\left(\mathrm{OD}_{660}\right)$.

During the resazurin incubation, the color of the solution containing the indicator cells in the absence of AZA (negative control) changed from blue to pink and this color change was determined by measuring the $\mathrm{OD}_{572}$ value for resorufin and $\mathrm{OD}_{600}$ for resazurin and expressed as the $\mathrm{OD}_{572} / \mathrm{OD}_{600}$ ratio. In the absence of AZA, the cells were able to grow under the low- $-\mathrm{CO}_{2}$ condition relying on their expressed hCAII, which led to the color change, while the sample without the indicator cells remained blue. In the sample containing the indicator cells and AZA at a concentration sufficient to inhibit the hCAII, the color remained blue with an $\mathrm{OD}_{572} / \mathrm{OD}_{600}$ ratio that was lower than that without the inhibitor (negative control).

An optimal initial yeast cell density is one of the important parameters of the assay. With too high cell density $\left(0.5-1 \times 10^{6}\right.$ cells $\left.\mathrm{mL}^{-1}\right)$, the $\mathrm{OD}_{572} / \mathrm{OD}_{600}$ ratio in the test-wells containing AZA was higher than that in the negative control (Fig. 4a), which is due to the extensive reduction of resazurin into resorufin and then hydroresorufin (colorless) in the control-wells (Ramsdell et al. 1935). Whereas, an over twofold difference in the $\mathrm{OD}_{572} / \mathrm{OD}_{600}$ ratio between the control and AZAtreated cells was noted when using a yeast cell density of $0.5-1 \times 10^{5}$ cells $\mathrm{mL}^{-1}$ (Fig. 4a). This observation is consistent with those determined by visualization of the color change (Fig. 4b). However, at a lower yeast cell density $\left(1 \times 10^{4}\right.$ cells $\left.\mathrm{mL}^{-1}\right)$ there was no significant difference in the $\mathrm{OD}_{572} / \mathrm{OD}_{600}$ ratio between the control and AZA-treated wells (Fig. 4a). Therefore, under these conditions $0.5-1 \times 10^{5}$ cells $\mathrm{mL}^{-1}$ was the appropriate initial yeast cell density.

The result showed that the minimal effective dose of AZA determined by the optimized REMA method was $0.31 \mu \mathrm{M}$ (Fig. 5), which was 20- to 40-fold lower than that determined from the spot test on agar plates (6.25$12.5 \mu \mathrm{M}$; Fig. 3). Therefore, the REMA method significantly increased the sensitivity for the detection of this inhibitor compared to the spot test on agar plate. Furthermore, this assay system showed a potentially high specificity (Fig. 5c).

In this study, an in vivo screening method for CAIs that inhibit hCAII was developed utilizing a drug sensitive nce103 null mutant strain expressing and relying on a low level of hCAII as indicator cells in combination with a REMA assay for the HTS of potential novel drugs. The yeast-based in vivo assay system has several advantages over the conventional in vitro biochemical screening assay as follows. Since this screening procedure is based on living yeast cells, in contrast to the 
conventional in vitro biochemical screening procedures, only compounds that permeate through the cell surface, and compounds that are metabolically stable in vivo can be screened.

Since the assay is based on the growth inhibition of the assay cells, cytotoxic compounds will be also selected by the screening. These compounds, however, can be easily eliminated by examining the growth of the assay cells under the high- $\mathrm{CO}_{2}$ condition, where the cells do not depend on the hCAII activity for growth.

This screening procedure will potentially facilitate a high throughput screening system for detection of safer hCAII inhibitors that could be further developed as a drug, especially for tropical use in glaucoma treatment. However, the candidates obtained from this screening procedure still require further investigation for their hCAII specificity by screening for inhibitory activity against other CA isozymes.

\author{
Abbreviations \\ CA: carbonic anhydrase; hCAll: human carbonic anhydrase isozyme II; CAl: \\ carbonic anhydrase inhibitor.
}

\section{Authors' contributions}

AS participated in the experimental design, carried out the experiments and drafted the manuscript. CY designed the experiments and wrote the manuscript. JK provided cDNA containing hCAll. All authors read and approved the final manuscript.

\section{Author details}

${ }^{1}$ Department of Microbiology, Faculty of Science, Chulalongkorn University, Bangkok, Thailand. ${ }^{2}$ Department of Biochemistry, Faculty of Medicine, Chulalongkorn University, Bangkok, Thailand.

\section{Acknowledgements}

The authors thank the Doctoral Degree Chulalongkorn University 100th Year Birthday Anniversary, Overseas Research Experience Scholarship for Graduate Student, Chulalongkorn University and The Asahi Glass Foundation for financial support. We thank Dr. Warinthorn Chavasiri, Department of Chemistry, Faculty of Science, Chulalongkorn University, Thailand for avicennin, and Emeritus Prof. Tokichi Miyakawa of Hiroshima University, Japan for helpful discussion.

\section{Competing interests}

The authors declare that they have no competing interests.

\section{Availability of data and materials}

Data sharing not applicable to this article as no datasets were generated or analysed during the current study.

\section{Consent for publication}

Not applicable.

\section{Funding}

This study was funded by Doctoral Degree Chulalongkorn University 100th Year Birthday Anniversary, Overseas Research Experience Scholarship for Graduate Student, Chulalongkorn University (to AS) and The Asahi Glass Foundation (to CY).

Ethics approval and consent to participate Not applicable.

\section{Publisher's Note}

Springer Nature remains neutral with regard to jurisdictional claims in published maps and institutional affiliations.

Received: 17 July 2018 Accepted: 27 July 2018

Published online: 04 August 2018

\section{References}

Aguilera J, Van Dijken JP, De Winde JH, Pronk JT (2005) Carbonic anhydrase (Nce103p): an essential biosynthetic enzyme for growth of Saccharomyces cerevisiae at atmospheric carbon dioxide pressure. Biochem J 391(Pt 2):311-316. https://doi.org/10.1042/BJ20050556

Amberg DC, Burke DJ, Burke D, Strathern JN (2005) Method in yeast genetics 2005 edition, 2005th edn. Cold Spring Harbor Laboratory Press, New York

Bilsland E, Sparkes A, Williams K, Moss HJ, de Clare M, Pir P, Rowland J, Aubrey W, Pateman R, Young M, Carrington M, King RD, Oliver SG (2013) Yeastbased automated high-throughput screens to identify anti-parasitic lead compounds. Open Biol 3(2):120158. https://doi.org/10.1098/rsob.120158

Breuder T, Hemenway CS, Movva NR, Cardenas ME, Heitman J (1994) Calcineurin is essential in cyclosporin A- and FK506-sensitive yeast strains. Proc Natl Acad Sci USA 91(12):5372-5376

Carta F, Supuran CT (2013) Diuretics with carbonic anhydrase inhibitory action: a patent and literature review (2005-2013). Expert Opin Ther Pat 23(6):681-691. https://doi.org/10.1517/13543776.2013.780598

Clark D, Rowlett RS, Coleman JR, Klessig DF (2004) Complementation of the yeast deletion mutant DeltaNCE103 by members of the beta class of carbonic anhydrases is dependent on carbonic anhydrase activity rather than on antioxidant activity. Biochem J 379(Pt 3):609-615. https://doi. org/10.1042/BJ20031711

Cottier V, Barberis A, Luthi U (2006) Novel yeast cell-based assay to screen for inhibitors of human cytomegalovirus protease in a high-throughput format. Antimicrob Agents Chemother 50(2):565-571. https://doi. org/10.1128/AAC.50.2.565-571.2006

Daniel A, Anthony A, Boris B, Michael F, Igor S (2005) Drug discovery using yeast as a model system: a functional genomic and proteomic view. Curr Proteomics 2(1):1-13. https://doi.org/10.2174/1570164053507790

Davis RA, Vullo D, Maresca A, Supuran CT, Poulsen SA (2013) Natural product coumarins that inhibit human carbonic anhydrases. Bioorgan Med Chem 21(6):1539-1543. https://doi.org/10.1016/j.bmc.2012.07.021

Del Prete S, Vullo D, Fisher GM, Andrews KT, Poulsen SA, Capasso C, Supuran CT (2014) Discovery of a new family of carbonic anhydrases in the malaria pathogen Plasmodium falciparum - the eta-carbonic anhydrases. Bioorg Med Chem Lett 24(18):4389-4396. https://doi.org/10.1016/j. bmcl.2014.08.015

Gietz RD, Schiestl RH, Willems AR, Woods RA (1995) Studies on the transformation of intact yeast-cells by the Liac/S-DNA/Peg procedure. Yeast 11(4):355-360. https://doi.org/10.1002/yea.320110408

Giniger E, Varnum SM, Ptashne M (1985) Specific DNA binding of GAL4, a positive regulatory protein of yeast. Cell 40(4):767-774

Goughenour KD, Balada-Llasat JM, Rappleye CA (2015) Quantitative microplate-based growth assay for determination of antifungal susceptibility of Histoplasma capsulatum yeasts. J Clin Microbiol 53(10):3286-3295. https ://doi.org/10.1128/JCM.00795-15

Gueldener U, Heinisch J, Koehler GJ, Voss D, Hegemann JH (2002) A second set of loxP marker cassettes for Cre-mediated multiple gene knockouts in budding yeast. Nucleic Acids Res 30(6):e23

Hemmi K, Julmanop C, Hirata D, Tsuchiya E, Takemoto JY, Miyakawa T (1995) The physiological roles of membrane ergosterol as revealed by the phenotypes of Syr1/Erg3 null mutant of Saccharomyces-cerevisiae. Biosci Biotech Biochem 59(3):482-486. https://doi.org/10.1271/bbb.59.482

Hong M, Fitzgerald MX, Harper S, Luo C, Speicher DW, Marmorstein R (2008) Structural basis for dimerization in DNA recognition by Gal4. Structure 16(7):1019-1026. https://doi.org/10.1016/j.str.2008.03.015 
Krungkrai J, Scozzafava A, Reungprapavut S, Krungkrai SR, Rattanajak R, Kamchonwongpaisan S, Supuran CT (2005) Carbonic anhydrase inhibitors. Inhibition of Plasmodium falciparum carbonic anhydrase with aromatic sulfonamides: towards antimalarials with a novel mechanism of action? Bioorg Med Chem 13(2):483-489. https://doi.org/10.1016/j. bmc.2004.10.015

Liang SD, Marmorstein R, Harrison SC, Ptashne M (1996) DNA sequence preferences of GAL4 and PPR1: how a subset of Zn2 Cys6 binuclear cluster proteins recognizes DNA. Mol Cell Biol 16(7):3773-3780

Lindskog S (1997) Structure and mechanism of carbonic anhydrase. Pharmacol Ther 74(1):1-20

Liu J, Farmer JD Jr, Lane WS, Friedman J, Weissman I, Schreiber SL (1991) Calcineurin is a common target of cyclophilin-cyclosporin A and FKBPFK506 complexes. Cell 66(4):807-815

Livak KJ, Schmittgen TD (2001) Analysis of relative gene expression data using real-time quantitative PCR and the 2(-Delta Delta C(T)) method. Methods 25(4):402-408. https://doi.org/10.1006/meth.2001.1262

Lomelino CL, Supuran CT, McKenna R (2016) Non-classical inhibition of carbonic anhydrase. Int J Mol Sci. https://doi.org/10.3390/ijms17071150

Marmorstein R, Carey M, Ptashne M, Harrison SC (1992) DNA recognition by GAL4: structure of a protein-DNA complex. Nature 356(6368):408-414. https://doi.org/10.1038/356408a0

Masini E, Carta F, Scozzafava A, Supuran CT (2013) Antiglaucoma carbonic anhydrase inhibitors: a patent review. Expert Opin Ther Pat 23(6):705-716. https://doi.org/10.1517/13543776.2013.794788

Miyamoto Y, Machida K, Mizunuma M, Emoto Y, Sato N, Miyahara K, Hirata D, Usui T, Takahashi H, Osada H, Miyakawa T (2002) Identification of Saccharomyces cerevisiae isoleucyl-tRNA synthetase as a target of the G(1)-specific inhibitor reveromycin A. J Biol Chem 277(32):28810-28814. https://doi.org/10.1074/jbc.M203827200

Monti SM, Supuran CT, De Simone G (2013) Anticancer carbonic anhydrase inhibitors: a patent review (2008-2013). Expert Opin Ther Pat 23(6):737749. https://doi.org/10.1517/13543776.2013.798648

Panthan B (2011) Expression of Plasmodium falciparum carbonic anhydrase in Saccharomyces cerevisiae deletion mutant $\Delta$ nce 103. Master of Science (Microbiology), Chulalongkorn University
Piecuch A, OblakE (2014) Yeast ABC proteins involved in multidrug resistance. Cell Mol Biol Lett 19(1):1-22. https://doi.org/10.2478/s11658-013-0111-2

Rampersad SN (2012) Multiple applications of Alamar Blue as an indicator of metabolic function and cellular health in cell viability bioassays. Sensors (Basel) 12(9):12347-12360. https://doi.org/10.3390/s120912347

Ramsdell GA, Johnson WMT, Evans FR (1935) Investigation of resazurin as an indicator of the sanitary condition of milk. J Dairy Sci 18(11):705-717. https://doi.org/10.3168/jds.S0022-0302(35)93193-9

Rusnak F, Mertz P (2000) Calcineurin: form and function. Physiol Rev 80(4):1483-1521. https://doi.org/10.1152/physrev.2000.80.4.1483

Sambrook J, Fritsch EF, Maniatis T (1989) Molecular cloning: a laboratory manual. Cold Spring Harbor Laboratory Press, Cold Spring Harbor

Scozzafava A, Supuran CT, Carta F (2013) Antiobesity carbonic anhydrase inhibitors: a literature and patent review. Expert Opin Ther Pat 23(6):725735. https://doi.org/10.1517/13543776.2013.790957

Shitamukai A, Mizunuma M, Hirata D, Takahashi H, Miyakawa T (2000) A positive screening for drugs that specifically inhibit the $\mathrm{Ca}^{2+}$-signaling activity on the basis of the growth promoting effect on a yeast mutant with a peculiar phenotype. Biosci Biotechnol Biochem 64(9):1942-1946

Sly WS, Hu PY (1995) Human carbonic anhydrases and carbonic anhydrase deficiencies. Annu Rev Biochem 64:375-401. https://doi.org/10.1146/ annurev.bi.64.070195.002111

Sugiura R, Sio SO, Shuntoh H, Kuno T (2001) Molecular genetic analysis of the calcineurin signaling pathways. Cell Mol Life Sci 58(2):278-288. https:// doi.org/10.1007/PL00000855

Supuran CT (2008) Carbonic anhydrases: novel therapeutic applications for inhibitors and activators. Nat Rev Drug Discov 7(2):168-181. https://doi. org/10.1038/nrd2467

Supuran CT, Scozzafava A (2000) Carbonic anhydrase inhibitors and their therapeutic potential. Expert Opin Ther Pat 10(5):575-600. https://doi. org/10.1517/13543776.10.5.575

\section{Submit your manuscript to a SpringerOpen ${ }^{\odot}$ journal and benefit from:}

- Convenient online submission

- Rigorous peer review

- Open access: articles freely available online

- High visibility within the field

- Retaining the copyright to your article

Submit your next manuscript at $\boldsymbol{\nabla}$ springeropen.com 